\title{
TEMEL OTURMA HESAPLARINDA GELENEKSEL YÖNTEM VE SONLU ELEMANLAR YÖNTEMINIIN KARŞILAŞTIRILMASI
}

\author{
Sıddıka Nilay KESKİN¹, Akten CENGIZHAN ${ }^{*}$
}

1Süleyman Demirel Üniversitesi, Mühendislik Fakültesi, İnşaat Mühendisliği Bölümü, Isparta, Türkiye

\begin{tabular}{ll}
\hline Anahtar Kelimeler & Öz \\
\hline Kil, & Bu çalışmada, farklı zemin profilleri ele alınarak temellerin oturma hesabı için \\
Oturma hesabı, & gerekli tüm laboratuvar deneyleri yapılmıştır. Bu deneyler sonucunda zemin \\
PLAXIS $3 D$, & profillerinin oluşturulmasından sonra temelde geleneksel yöntemle konsolidasyon \\
Sonlu elemanlar yöntemi, & oturması hesapları yapılmıştır. Aynı veriler kullanılarak PLAXIS 3D üç boyutlu sonlu \\
Temel. & eleman paket programı ile sayısal analizler gerçekleştirilmiştir. Geleneksel \\
& yöntemle ve sonlu elemanlar analizlerinden elde edilen sonuçlar birbirleriyle \\
& karşılaştırılmış grafik olarak sunulmuştur. Bu karşılaştırmaların sonucunda \\
& temellerin oturma miktarının hesaplanmasında geleneksel yöntem yollarılala sonlu \\
& elemanlar paket programı analizleri birbirine çok yakın sonuçlar vermiştir. Bu \\
& sonuçlara bakılarak hata payının \%1'den az olduğu gözlemlenmiştir. \\
\hline
\end{tabular}

\section{COMPARISON OF CONVENTIONAL METHOD AND FINITE ELEMENTS METHOD IN THE SETTLEMENT CALCULATIONS OF FOUNDATIONS}

\begin{tabular}{l} 
Keywords \\
\hline Clay, \\
Settlement calculation, \\
PLAXIS $3 D$, \\
Finite element method, \\
Basic.
\end{tabular}
Basic.

\begin{abstract}
In this study, all the laboratory experiments necessary for basic design were carried out by considering different soil profiles. As a result of these experiments, after the formation of the soil profiles, settlement calculations were made mainly by conventional method routes. Numerical analyzes were performed with using a finite element packet program for the same data The results obtained from the conventional method and the finite element analysis are presented graphically. As a result of these comparisons, the finite element package program analysis with conventional methods for calculating the sitting amount of the foundations gave very close results. Based on these results, it was observed that the margin of error was less than $1 \%$.
\end{abstract}

Alıntı / Cite

Keskin, S.N., Cengizhan, A., (2019). Temel Oturma Hesaplarında Geleneksel Yöntem ve Sonlu Elemanlar Yönteminin Karşılaştırılması, Mühendislik Bilimleri ve Tasarım Dergisi, 7(1), 136-144.

Yazar Kimliği / Author ID (ORCID Number)

S.N. Keskin, 0000-0002-0367-943X

A. Cengizhan, 0000-0002-2081-5384
Makale Süreci / Article Process

Basvuru Tarihi / Submission Date

Revizyon Tarihi / Revision Date

Kabul Tarihi / Accepted Date

Yayım Tarihi / Published Date

\begin{tabular}{|l}
21.05 .2018 \\
12.12 .2018 \\
19.12 .2018 \\
25.03 .2019
\end{tabular}

\section{Giriş}

Kil ve silt gibi ince taneli zeminler, iri taneli zeminlerin aksine ortamda suyun varlığına bağlı olarak şişme veya büzülme eğilimi gösterdikleri için, mühendislik açısından, genellikle sorunlu malzemeler olarak bilinmektedir. Ayrıca ince taneli zeminlerin belirli bir yük altında sıkışma süreçlerinin uzun zaman alması, yapının inşası ile başlayan oturma süreçlerinin önceden analiz edilmesini zorunlu kılmaktadır. Bu nedenle projelerde zeminin plastik ve indeks özelliklerinin yanı sıra sıkışma parametrelerinin de belirlenmesi gereklidir. Ancak bazen bu parametrelerin belirlenmesi zaman veya ekonomik nedenlerden dolayı zor olmaktadır. Konsolidasyon özellikleri ile birlikte, zeminlerin sınıflanabilmesi için plastik özelliklerinin de belirlenmesi gerekebilmektedir (Sünnetçi ve Ersoy, 2016).

Zemin davranışlarına bağlı olarak, mühendislik

\footnotetext{
* ilgili yazar / Corresponding author: cengizhanakten@gmail.com, +90537-846-8384
} 
yapılarında deformasyonların gelişmesi muhtemeldir. $\mathrm{Bu}$ deformasyonlar yapının altında bulunan zeminin içinde bulunduğu gerilme koşullarının değişmesine sebep olur. Gerilme koşullarında meydana gelen artış dolayısıyla yapı altında bulunan zeminde oturmalar meydana gelir. Zemin kitlesinde gerilmelerin herhangi bir sebeple azalması sonucunda veya su içeriklilerinde oluşabilecek değişmeler sonucunda şişmeler gözlenebilir. Oturma ve şişme potansiyeli yüksek zeminler üzerinde inşa edilen mühendislik yapıları zeminlerin şişme özelliklerinden kaynaklanan kuvvetlere maruz kalırlar. $\mathrm{Bu}$ ise üzerinde bulunan mühendislik yapısının taşıyıcı unsurlarını etkilemekte ve yapılarda deformasyonların oluşmasına neden olmaktadır. Oturma ve șişme özelliklerinden dolayı meydana gelen zemin kitlesinin hacmindeki değişiklikler zeminle ilgili projelerin tasarımında en etkili faktör olmaktadır (Yılmaz ve Çelik, 2012).

Zemin elastoplastik, homojen olmayan ve anizotrop bir malzemedir. PLAXIS (statik, dinamik gerilme analiz ve modelleme programı) zemin için geliştirilmiş bir sonlu elemanlar programıdır. Avcı ve Tuncan (2008), Subaşı vd. (2012), Çetin vd. (2012), Adatepe vd. (2012), zeminin modellenmesinde PLAXIS programını kullanmışlardır.

Bu çalıșmada, farklı zemin profilleri ele alınarak bu zemin profillerinde yer alan ince ve iri daneli zeminlerin bir temellerin oturma hesaplamaları için gerekli tüm laboratuvar deneyleri yapılması amaçlanmıştır. $\mathrm{Bu}$ deneyler sonucunda zemin profilleri oluşturulup temelde konsolidasyon oturmaları hesabı yapılacaktır. Aynı veriler PLAXIS 3D üç boyutlu sonlu eleman paket programı ile yapılarak sonuçlar çalışmanın amacına uygun olarak karşılaştırılacaktır.

\section{Bilimsel Yazın Taraması}

Bağrıaçlk ve Laman (2010), çalışmalarında kumlu zeminler üzerine oturan farklı geometrilerdeki yüzeysel temellerden dolayı zemin içinde oluşan ilave düşey gerilme davranışları laboratuvar model deneyleri yapılarak araştırmışlardır. Bu amaçla zemin içerisinde belirlenen derinlikteki yatay düzlemler boyunca 3 farklı geometride ki yüzeysel temellerden dolayı meydana gelen ilave düşey gerilme değerleri ölçülerek şekil etkisi incelemişlerdir. Sonuç olarak; farklı geometrilerdeki temellerde şekil etkisinin önemli mertebelerde olduğu gözlemlemişlerdir.

Örnek vd. (2014), tarafından kum zemine oturan eksantrik yüklü şerit temellerin analizi incelenmiştir ve yük eksantrisitesi arttıkça nihai taşıma gücünün azaldığı görülmüştür.

Türedi ve Örnek (2015), çalışmalarında dikdörtgen kesitli model temelin farklı yükleme koşullarında zemine oturması sonucunda meydana gelen düşey gerilme ve taşıma gücü değişimleri deneysel ve teorik olarak araştırmışlardır. Sonuç olarak eksantrisite arttıkça taşıma gücü değerlerinin azaldığını göstermişlerdir. Aynı zamanda merkezden uzaklaşıldıkça da gerilme değerlerinde azalmalar tespit etmişlerdir. Model deney sonuçları ile teorik sonuçların da birbirleri ile uyumlu olduklarını belirtmişlerdir.

Mısır ve Laman (2015), çalışmalarında yoğrulmuş kil zeminler üzerine inşa edilen granüler dolgu tabakasına oturan dairesel temellerin yük taşıma kapasiteleri, 6 ve $9 \mathrm{~cm}$ çaplı temeller için, laboratuvar model deneyleri ile incelemişlerdir. İki farklı temel çapı için karșılaștırma yapıldığında, ölçek etkisinin bulunmadığı görülmüștür. Deneysel veriler literatür de sunulan analitik bir bağıntı ile karşılaştırılarak, uyum içerisinde olduğunu gözlemlemişlerdir.

Sert vd. (2010), çalışmalarında sonlu elemanlar yöntemi ile analizi için geliştirilmiş bir yazılım olan PLAXIS 2D yazılımının "Hassaslık Analizi ve Parametre Değişimi” seçeneği kullanmışlardır. Uygulama, üstte $5 \mathrm{~m}$ kil ve altında $15 \mathrm{~m}$ kumdan oluşan $20 \mathrm{~m}$ kalınlığındaki bir zemin kesitinde oturan bir sürekli temelin oturma davranışını ele almaktadır. Kil için elastisite modülü, kohezyon, kayma direnci açısı ve ara yüzey katsayısının, kum için elastisite modülü ve kayma direnci açısının etkisi incelenmiş ve tüm sonuçlar değerlendirildiğinde; modeldeki koşullara göre kildeki kohezyon değerinin kumdaki kayma direnci açısının elastisite modüllerine göre sonuçlara daha fazla etki ettiğini gözlemlemişlerdir.

Ekinci ve Orakoğlu (2013), çalışmalarında tekil ve uniform yükün temel zemini üzerinde oluşturdukları gerilmeler sayısal gerilme çözümlemesi yöntemiyle bilgisayar ortamında modellemișlerdir. Zeminlerin elek analizi, kıvam limit değerleri, optimum su muhtevası, maksimum kuru birim hacim ağırlık ve şişme yüzdeleri belirlemişlerdir. Sonuç olarak; Phase 2 bilgisayar programı ile modellenen zeminlerde uniform yük altında oluşan gerilme dağılımı ile tekil yük altındaki gerilme dağılımı arasında farkları gözlemlemişlerdir. Her iki yükün gösterdiği gerilme değerleri zemin emniyet gerilmesinden düşük olduğu anlaşılmıştır. Böylece sayısal gerilme çözümlemesi yöntemi sayesinde çok daha kısa sürede yapı-zemin etkileşimi ve zemin gerilme değerlerini belirlemişlerdir.

Enkhtur vd. (2013), yüzeysel temellerin oturmasının nümerik analizlerle hesaplanmasını ele aldığı çalışmasında üç farklı nümerik analiz kullanarak oturma hesapları yapmıştır. Basıncın, gerilme dağılımı, oturmayı etkileyen faktörlerin ve sonlu eleman tabakası kalınlığının çözümlerde oldukça etkili olduğunu belirtmişlerdir.

Brinkgreve vd. (2004), çalışmalarında sonlu elemanlar yöntemine dayanan iki boyutlu PLAXIS 2D (Finite Element Code for Soil and Rock Analysis) 
bilgisayar yazılımını kullanmışlardır. Programda, farklı tür zeminlere oturan temellerin deformasyon analizleri yapılabilmekte ve herhangi bir zemin probleminin gerilme-deformasyon ilişkileri tanımlanabilmektedir. Aynı zamanda programda zemin parametreleri, inşaat aşamaları, yükleme ve sınır koşulları girilerek problemin ayrıntılı ve hassas bir şekilde modellenmesi sağlanmaktadır. Kil ve kum zemin davranışının modellenmesi için Mohr Coulomb Modeli kullanmışlardır.

\section{Materyal ve Yöntem}

\subsection{Materyal}

$\mathrm{Bu}$ çalışmada Isparta ilimizin bazı ilçelerinden getirilen iki farklı zemin numuneleri üzerinde çalışılmıştır. Bunlar; Şarkikaraağaç (Numune A) ve Uluborlu (Numune B) olarak adlandırılan zemin numuneleridir. Araziden alınan numuneler üzerinde laboratuvar deneyleri yapılmıştır. Süleyman Demirel Üniversitesi Zemin Mekaniği Laboratuvarında zeminlerin endeks özelliklerini belirlemek için elek analizi, hidrometre analizi, kıvam limitleri, piknometre deneyi ve kompaksiyon deneyi yapılmıştır. Kompaksiyon deneyinden elde edilen maksimum kuru birim hacim ağırlık ve optimum su muhtevasında numuneler hazırlanarak konsolidasyon deneyine tabi tutulmuştur.

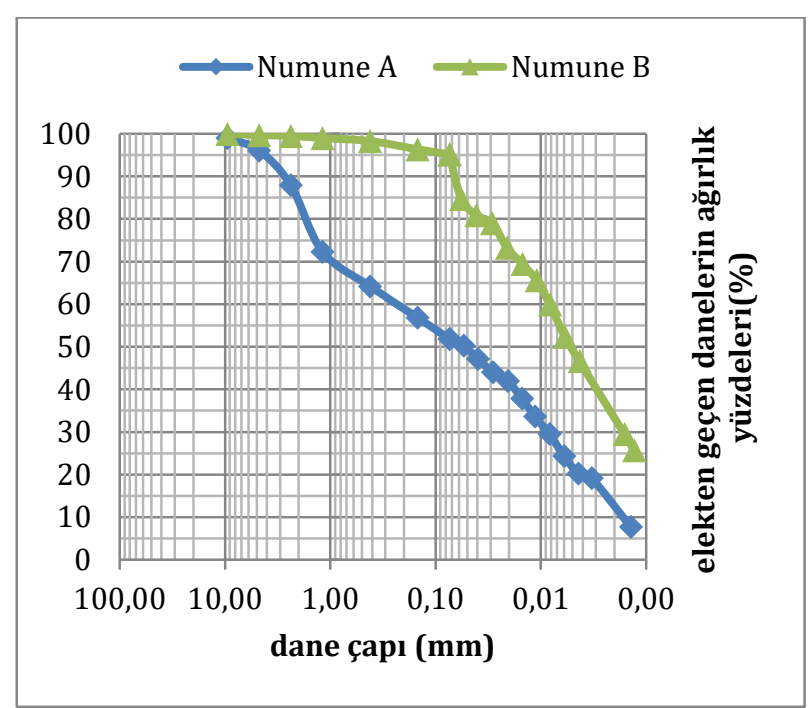

Şekil 1. Kullanılan zemin numunelerine ait granülometri eğrisi

Tablo 1. Kullanılan zemin numunelerine ait kıvam limitleri ve piknometre deneyi sonuçları

\begin{tabular}{|c|c|c|}
\hline Numune & A & B \\
\hline Plastik Limit(\%) & 18 & 16 \\
\hline Likit Limit(\%) & 39 & 56 \\
\hline Rötre Limiti(\%) & 14 & 11,6 \\
\hline Plastisite İndisi(\%) & 21 & 40 \\
\hline ys (gr/cm 3 ) & 2,84 & 2,70 \\
\hline
\end{tabular}

Temin edilen zemin numunelerin zemin endeks özellikleri belirlenmiștir. Plastisite kartına göre zemin numunelerinin sınıflandırılması yapılmıştır. TS 1500 ve TS 1900 zemin standartlarına göre A numunesinin düşük plastisiteli killi(CL) zemin numunesi olduğuna, B numunesinin yüksek plastisiteli killi(CH) zemin numunesi olduğu tespit edilmiştir.

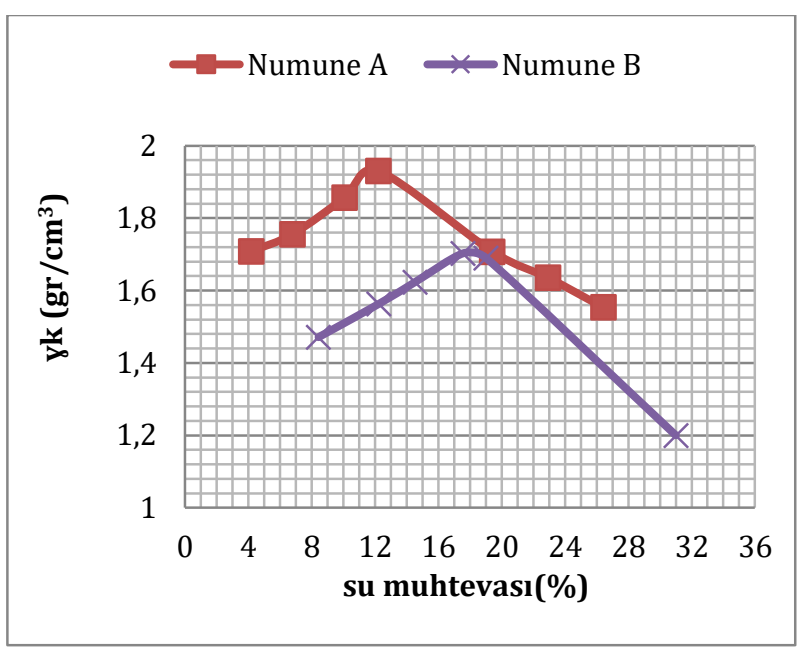

Şekil 2. Kullanılan numunelere ait kompaksiyon eğrileri

Tablo 2. Kullanılan zemin numunelerine ait kompaksiyon deneyi sonuçları

\begin{tabular}{|l|l|l|}
\hline Numune & $\begin{array}{c}\text { Wopt } \\
\text { (\%) }\end{array}$ & $\begin{array}{c}\boldsymbol{\gamma}_{\mathbf{k m a x}} \\
\mathbf{( g r} / \mathbf{c m}^{3} \mathbf{)}\end{array}$ \\
\hline A & 12 & 1,93 \\
\hline B & 17,55 & 1,70 \\
\hline
\end{tabular}

\subsection{Yöntem}

$\mathrm{Bu}$ çalışmada kullanılan numunelerin oturma değerlerinin belirlenmesi için ödometre deneyi, kayma direnci için serbest basınç deneyi, kesme kutusu deneyi ve üç eksenli basınç deneyi yapılmıştır. $\mathrm{Bu}$ deneyler proktor deneyinden elde edilen optimum su muhtevası ve maksimum kuru birim hacim ağırlık değerlerinde yapılmıştır. Oturma hesabı yapılabilmesi için gerekli olan parametreler, yapılan konsolidasyon deneyleri sonucunda belirlenmiştir. Seçilen zemin profilleri üzerinde yapılacak olan binalardan gelecek yükler göz önüne alınarak temel tipi olarak radye temel seçilmiştir. Çalışma kapsamında konsolidasyon oturmaları hesabı yapılmıştır. Konsolidasyon oturmaları hesabı için aşağıdaki eşitlik kullanılmıştır (Denklem1).

$\mathrm{S}_{\mathrm{c}}=\mathrm{m}_{\mathrm{v}} \cdot \mathrm{H} \cdot \Delta \sigma^{\prime}$

Eşitlikte; $\mathrm{S}_{\mathrm{c}}$ tabakanın konsolidasyon oturması miktarı, $\Delta \sigma^{\prime}$ yüklemeden dolayı tabaka ortasında meydana gelen efektif gerilme artışı, $m_{v}$ hacimsel sıkışabilirlik katsayısı, H kil tabakasının kalınlığıdır. 


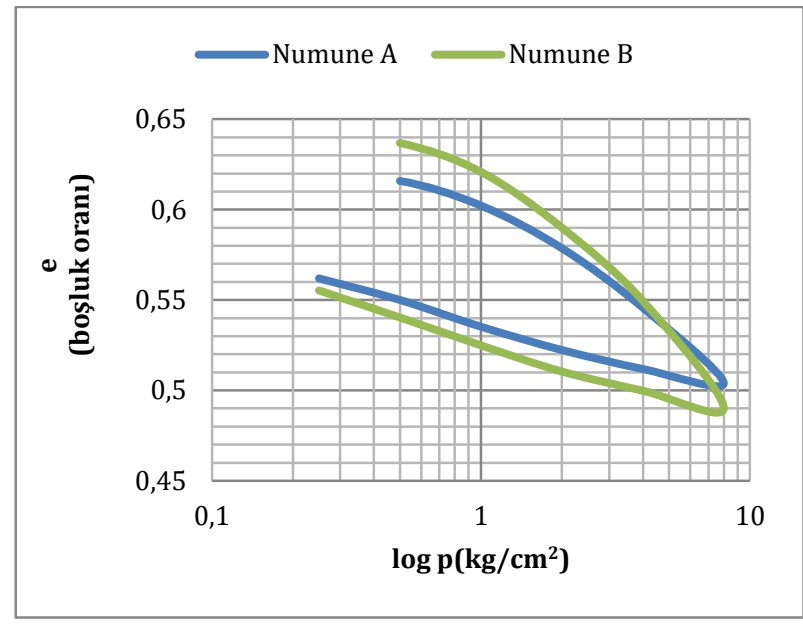

Şekil 3. Kullanılan numunelerin konsolidasyon eğrileri

Tablo 3. Kullanılan numunelerin deney başlangıcındaki ve deney sonundaki boşluk oranı değerleri

\begin{tabular}{|l|c|c|}
\hline Numune & $\begin{array}{c}\mathbf{e}_{\mathbf{0}} \\
\text { (başlangıçtaki } \\
\text { boşluk oranı ) }\end{array}$ & $\begin{array}{c}\text { en } \\
\text { (deney } \\
\text { sonundaki } \\
\text { boşluk oranı) }\end{array}$ \\
\hline A & 0,623 & 0,562 \\
\hline B & 0,64 & 0,555 \\
\hline
\end{tabular}

Zemin profillerinde CL numunesi (Profil A) ve $\mathrm{CH}$ numunesi (Profil B) kullanılmıştır. Numune A ve Numune B YASS(Yer Altı Su Seviyesi)'nin altında olduğu için doygun birim hacim ağırlık kullanılmıştır YASS'nin üzerinde 2,5 m kalınlığında kum tabakası ve altında 7,5 m'lik kil tabakası kullanılmıştır. Temel kalınlığı 0,8 m alınmıştır. Kil tabakasının altında profilin son katmanı olan geçirimsiz sağlam zemin ana kaya seçilmiştir. 7,5 m derinlik için killerin konsolidasyon oturmaları hesapları yapılmıştır.

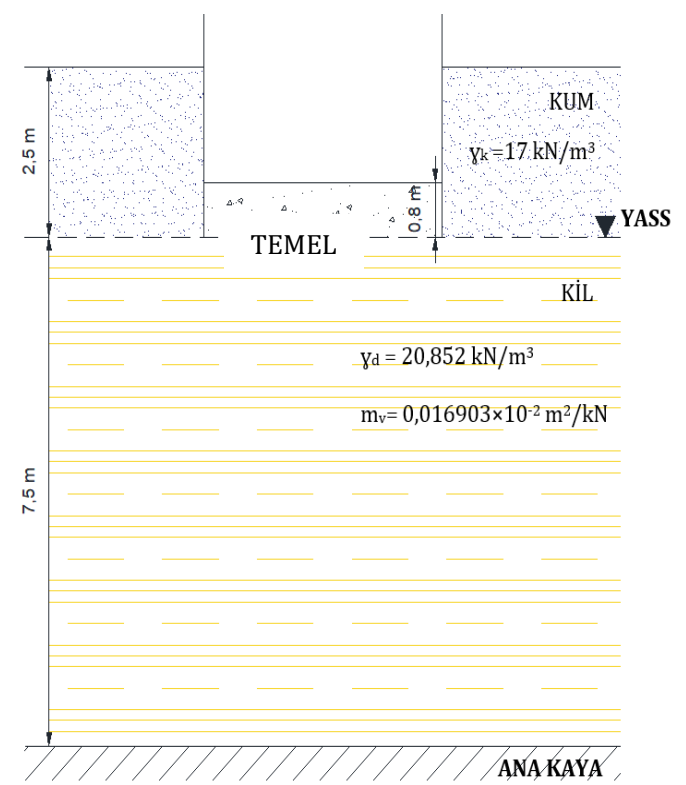

Şekil 4. Profil A için oluşturulan zemin profili

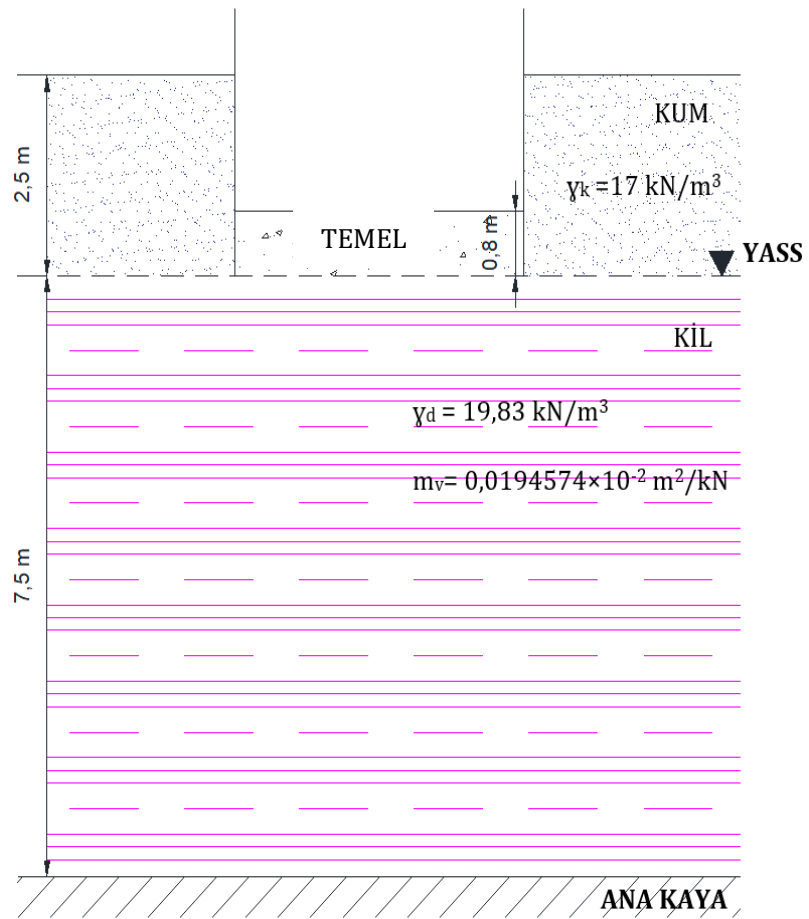

Şekil 5. Profil B için oluşturulan zemin profili

Tablo 4. Radye temelin özellikleri

\begin{tabular}{|l|l|}
\hline $\mathrm{B}(\mathrm{m})$ - genişlik & 22.1 \\
\hline $\mathrm{L}(\mathrm{m})-$ uzunluk & 8.5 \\
\hline Temel kalınlığ $(\mathrm{m})$ & 0,8 \\
\hline Zbeton $\left(\mathrm{kN} / \mathrm{m}^{3}\right)$ & 25 \\
\hline
\end{tabular}

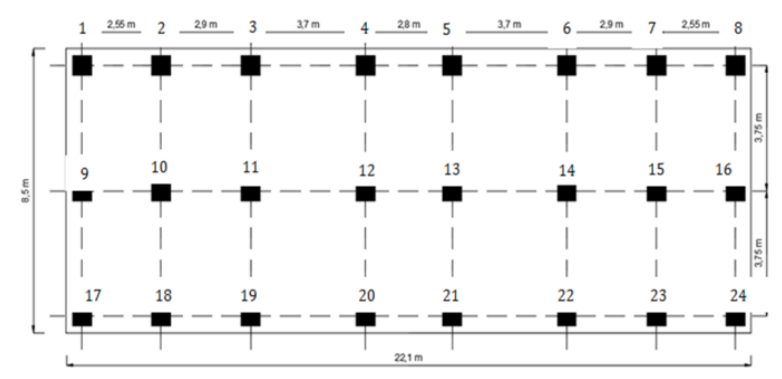

Şekil 6. Temel hesabında kullanılacak kolon aplikasyon planı

Tablo 5. Radye temele etki eden kolon yükleri

\begin{tabular}{|c|c|c|c|c|c|c|c|}
\hline $\begin{array}{c}\text { Kolon } \\
\text { kodu }\end{array}$ & $\begin{array}{c}\text { Yük } \\
\text { (ton) }\end{array}$ & $\begin{array}{c}\text { Kolon } \\
\text { kodu }\end{array}$ & $\begin{array}{c}\text { Yük } \\
\text { (ton) }\end{array}$ & $\begin{array}{c}\text { Kolon } \\
\text { kodu }\end{array}$ & $\begin{array}{c}\text { Yük } \\
\text { (ton) }\end{array}$ & $\begin{array}{c}\text { Kolon } \\
\text { kodu }\end{array}$ & $\begin{array}{c}\text { Yük } \\
\text { (ton) }\end{array}$ \\
\hline $\mathbf{1}$ & 40,383 & $\mathbf{7}$ & 59,686 & $\mathbf{1 3}$ & 85,268 & $\mathbf{1 9}$ & 54,955 \\
\hline $\mathbf{2}$ & 59,669 & $\mathbf{8}$ & 40,337 & $\mathbf{1 4}$ & 87,511 & $\mathbf{2 0}$ & 40,032 \\
\hline $\mathbf{3}$ & 55,280 & $\mathbf{9}$ & 41,951 & $\mathbf{1 5}$ & 75,219 & $\mathbf{2 1}$ & 40,019 \\
\hline $\mathbf{4}$ & 41,891 & $\mathbf{1 0}$ & 75,163 & $\mathbf{1 6}$ & 41,921 & $\mathbf{2 2}$ & 54,927 \\
\hline $\mathbf{5}$ & 41,965 & $\mathbf{1 1}$ & 87,435 & $\mathbf{1 7}$ & 40,379 & $\mathbf{2 3}$ & 59,677 \\
\hline $\mathbf{6}$ & 55,262 & $\mathbf{1 2}$ & 85,288 & $\mathbf{1 8}$ & 59,613 & $\mathbf{2 4}$ & 40,683 \\
\hline
\end{tabular}

Çalışmanın amacına uygun olarak hem geleneksel yöntemle hem de sonlu elemanlar yöntemiyle (PLAXIS 3D Foundation) konsolidasyon oturması hesapları yapılıp sonuçlar birbirleriyle karşılaştırılmıştır. 


\section{Araştırma Bulguları}

\subsection{Konsolidasyon Oturmaları Hesabı Sonuçları}

Konsolidasyon deneyi sonucunda elde edilen hacimsel sıkışma katsayısı $\left(\mathrm{m}_{\mathrm{v}}\right)$ ve sıkışma sayıları $\left(\mathrm{a}_{\mathrm{v}}\right)$ Tablo 6'da verilmiştir. Porfil A ve B'de mevcut jeolojik yük ve ilave gerilme sonrası toplam yük $0.5-1.0 \mathrm{~kg} / \mathrm{cm}^{2}$ yük kademesine karşıllk geldiğinden $m_{v} v e a_{v}$ değerleri bu aralıktan alınmıştır.

Tablo 6. Kullanılan numunelere ait konsolidasyon parametreleri

\begin{tabular}{|c|c|c|c|}
\hline Numune & $\Delta \mathbf{p}\left(\mathbf{k g} / \mathbf{c m}^{2}\right)$ & $\mathbf{a}_{\mathbf{v}}\left(\mathbf{c m}^{2} \mathbf{~ k g )}\right.$ & $\mathbf{m}_{\mathbf{v}}\left(\mathbf{c m}^{2} / \mathbf{k g}\right)$ \\
\hline A & $0.5-1$ & 0,027314716 & 0,01690299 \\
\hline B & $0.5-1$ & 0,03184863 & 0,019457393 \\
\hline
\end{tabular}

Tablo 7. Profil A ve C 'de meydana gelecek konsolidasyon oturmaları sonuçları

\begin{tabular}{|c|c|c|}
\hline Profil & A & B \\
\hline$\sigma_{\text {net }}\left(\mathrm{kg} / \mathrm{cm}^{2}\right)$ & 0,5078 & 0,5078 \\
\hline $\mathbf{m}$ & 1,13 & 1,13 \\
\hline $\mathbf{n}$ & 2,95 & 2,95 \\
\hline $\mathbf{k}(\mathbf{I} \sigma)$ & 0,20985 & 0,20985 \\
\hline$\Delta \sigma_{\mathrm{v}}\left(\mathrm{kg} / \mathrm{cm}^{2}\right)$ & 0,1065 & 0,1065 \\
\hline $\mathrm{m}_{\mathrm{v}}\left(\mathrm{cm}^{2} / \mathrm{kg}\right)$ & 0,01690299 & 0,019457393 \\
\hline $\mathbf{H}(\mathbf{c m})$ & 750 & 750 \\
\hline$S_{c}(\mathrm{~cm})$ & 1,35 & 1,6 \\
\hline
\end{tabular}

Kil tabakalarının orta noktasında meydana gelecek ilave düşey gerilme hesapları uniform yüklü dikdörtgen alan yöntemi ile belirlenmiş, Profil A ve B'de meydana gelen konsolidasyon oturmaları bu ilave gerilmeler dikkate alınarak hesaplanmıștır. Konsolidasyon oturmaları hesabına ait parametreler ve konsolidasyon oturması miktarları Tablo 7'de gösterildiği gibidir.

\subsection{Sonlu Elemanlar Yöntemiyle Elde Edilen Sonuçları}

Çalışmada Profil A ve B 'nin modelleme tipi olarak hardening-soil modeli kullanılmıștır. $\mathrm{Bu}$ modelle konsolidasyonlu-drenajsız oturma hesabı yapılabilmektedir. Kumda kullanılan model parametresi Mohr-Coulomb modelidir. Duvar ve döşemelerde linear elastic modelleme kullanılmış olup bu modelin verileri yazılımın bize verdiği kendi değerlerdir. Maksimum oturmaların olduğu noktalar turuncu renkte verilirken minimum oturmaların olduğu noktalar mavi renkte verilmiștir. Şekil 7 ve 8'de Profil A'ya ait deforme olmuş durumu ve toplam oturmaları, Şekil 10 ve 11'de Profil B'ye ait deforme olmuş durumu ve toplam oturmaları göstermektedir.

Şekil 9'da Profil A'nın oturma-zaman grafiği verilmiştir. Burada 365'nci günde maksimum oturmanın 1,356 cm olduğu gözlemlenmiştir.

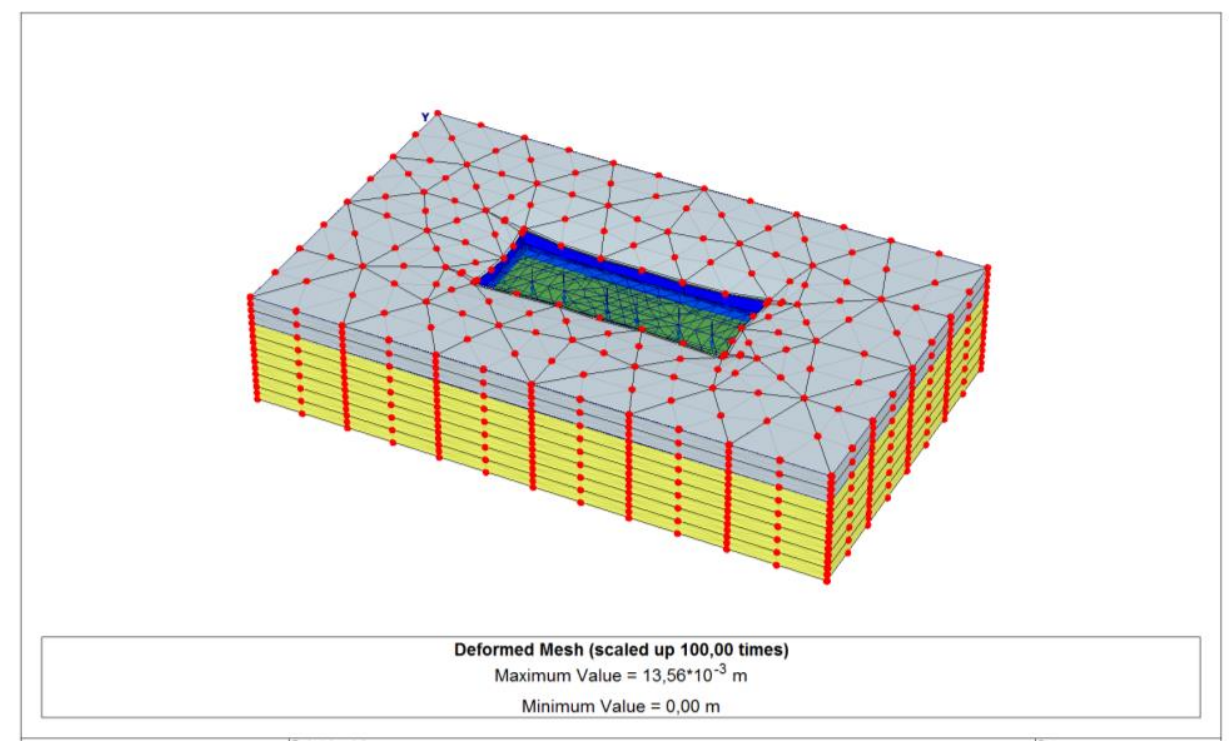

Şekil 7. Profil A'ya ait modelin deforme olmuş durumu 


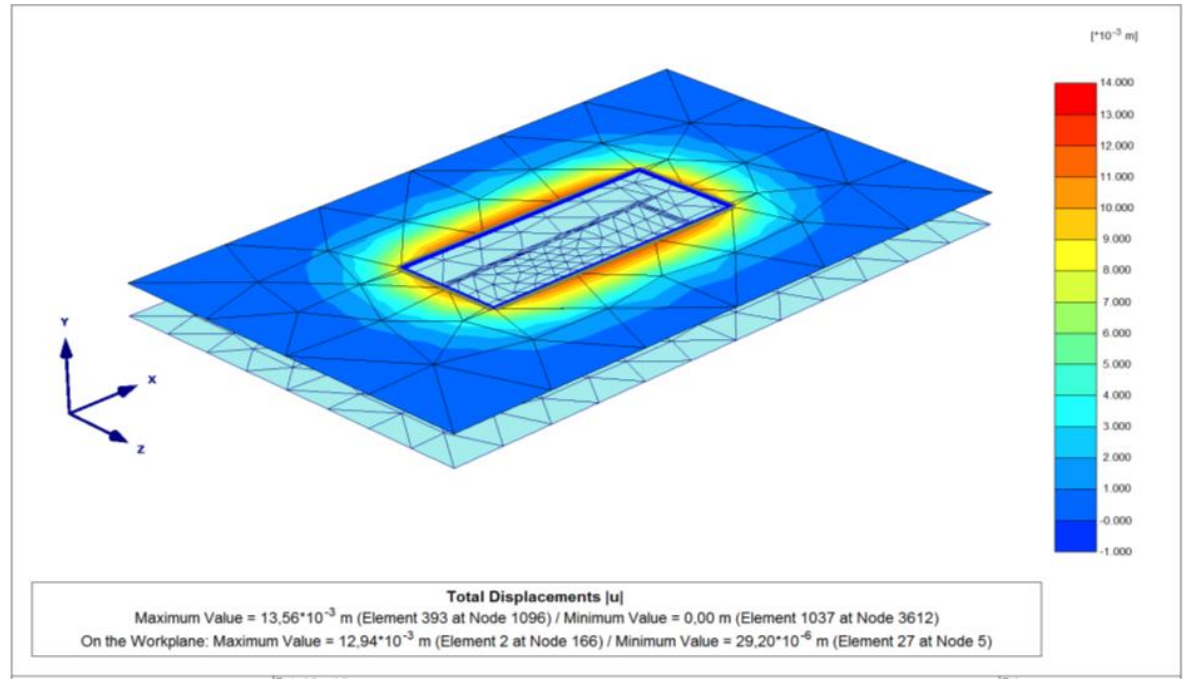

Şekil 8. Profil A'da meydana gelen toplam oturmalar

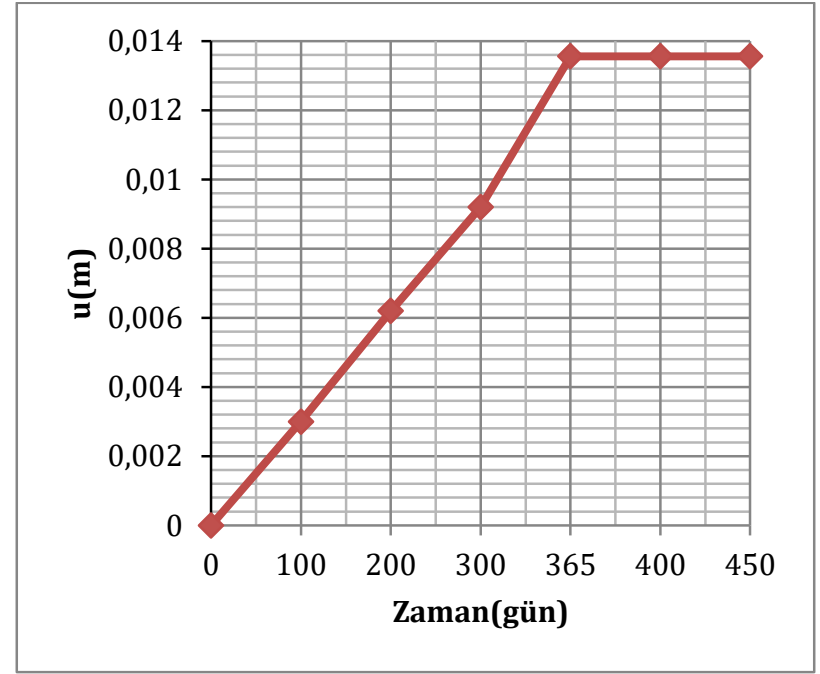

Şekil 9. Profil A'ya ait oturma - zaman grafiği

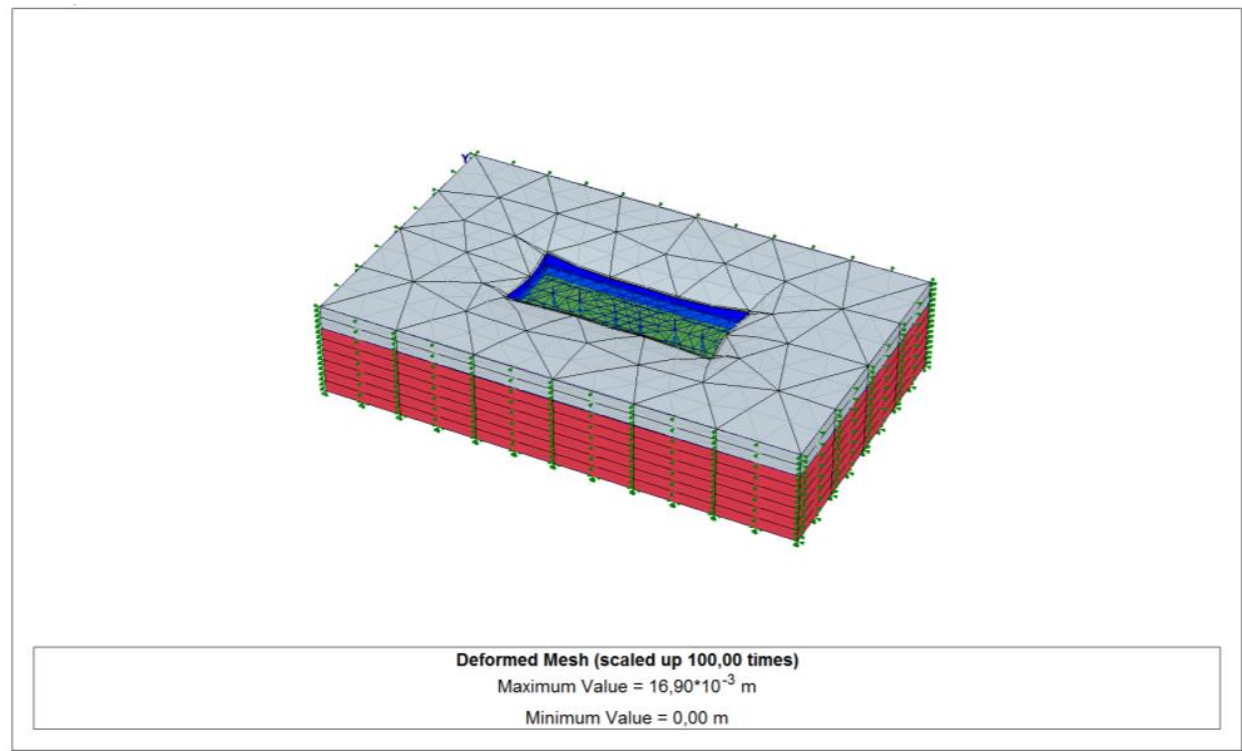

Şekil 10. Profil B’ye ait modelin deforme olmuş durumu 


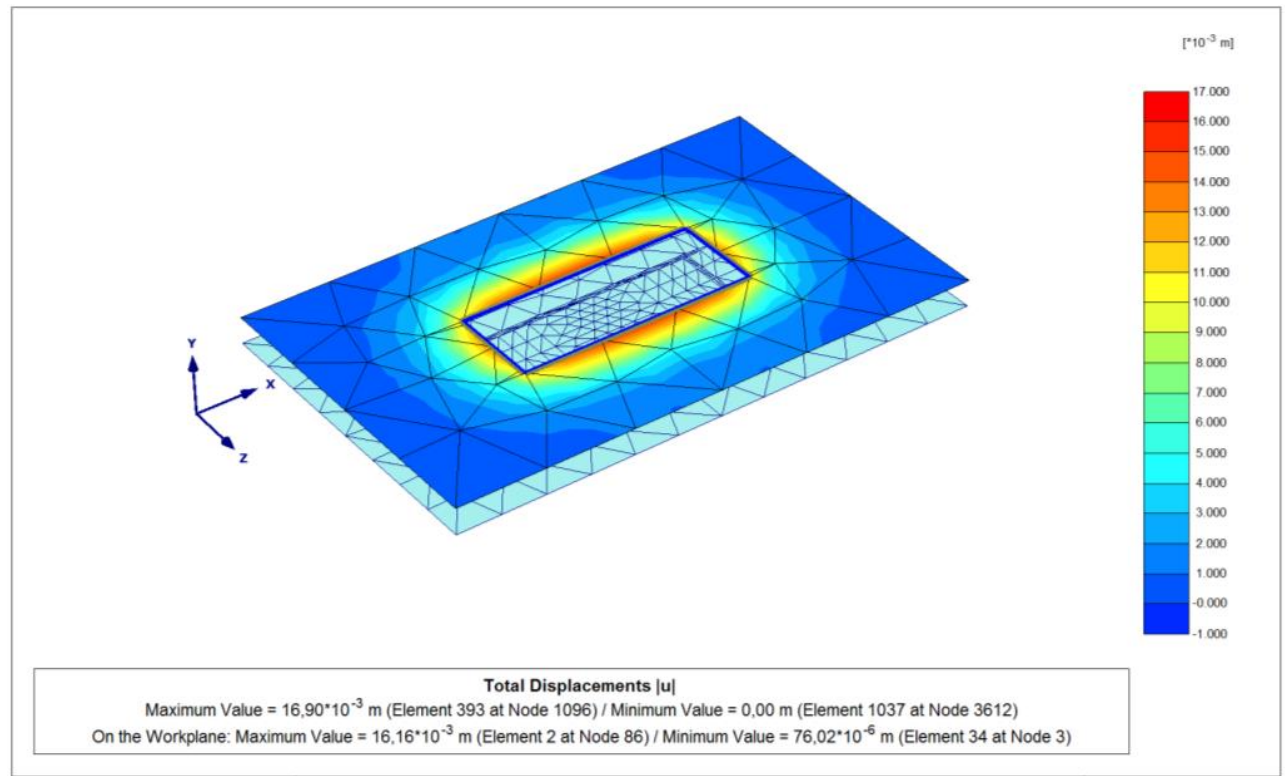

Şekil 11. Profil B'de meydana gelen toplam oturmalar

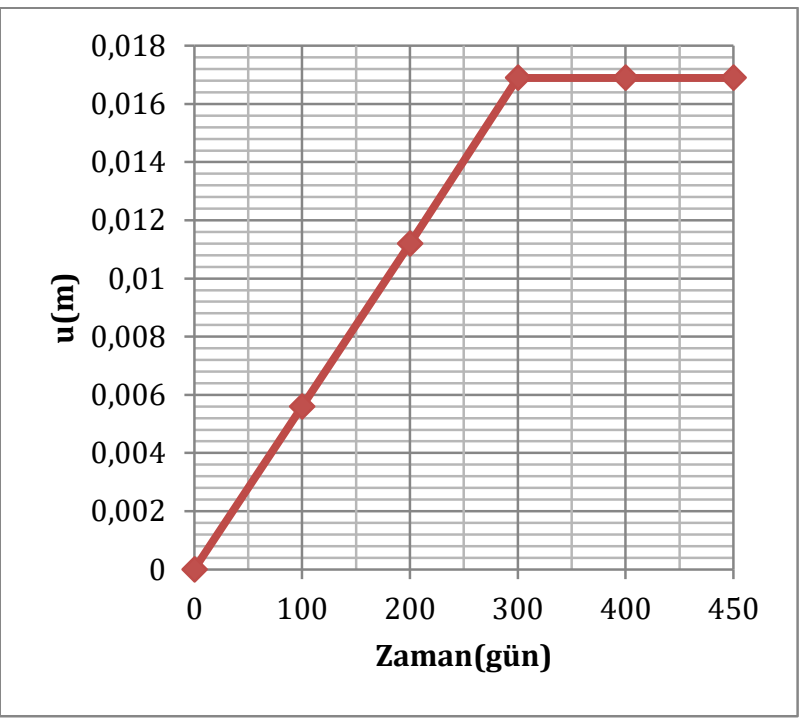

Şekil 12. Profil B’ye ait oturma - zaman grafiği Şekil 12'de Profil B'nin oturma-zaman grafiği verilmiştir. Burada 291'nci günde maksimum oturmanın 1,69 cm olduğu gözlemlenmiştir.

\subsection{Temellerin Oturma Hesaplarında Geleneksel Yöntem Ve Sonlu Elemanlar Yönteminin Karşılaştırılması}

Şekil 13 'te çalışmanın asıl amacı olan geleneksel yöntem ve sonlu elemanlar yöntemiyle (PLAXIS 3D) oturma miktarının karşılaştırılması yapılmıştır. Bu sonuçlara göre el hesabımızla yapılan oturma miktarı numune $A^{\prime}$ da $1,35 \mathrm{~cm}$ iken, PLAXIS 3D yazılımında $1,356 \mathrm{~cm}$ hesaplanmıştır. Numune B'nin el hesabındaki oturma miktarı 1,6 cm iken, PLAXIS 3D yazılımında $1,69 \mathrm{~cm}$ hesaplanmıștır. Buradan karşılaştırılma yapıldığında el hesabıyla yazılım hesabı arasında çok fazla fark olmadı̆̆ gözlemlenmiştir.

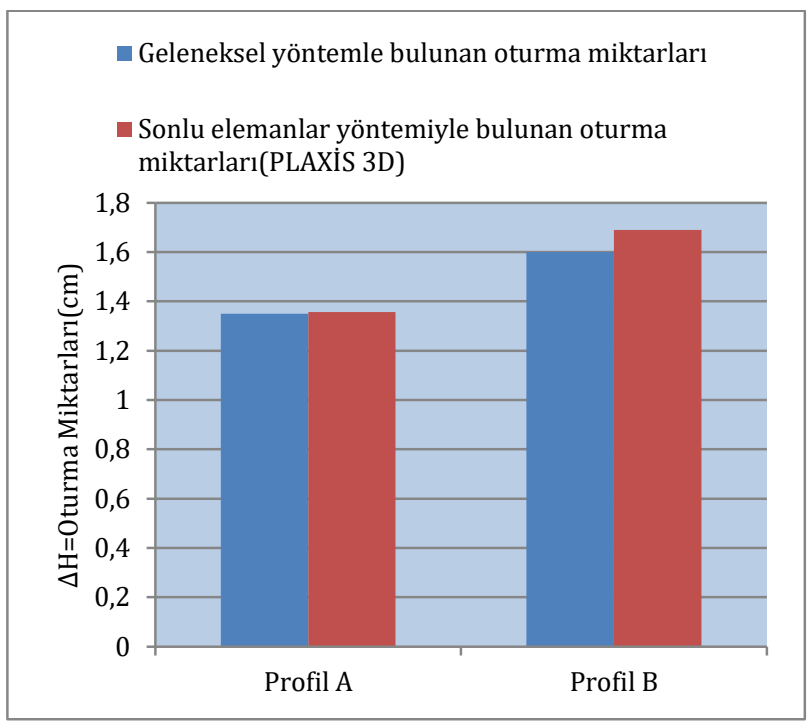

Şekil 13. Profil A ve B’nin geleneksel yöntemle ve sonlu elemanlar yöntemiyle oturma miktarlarının karşılaştırılması

\section{Sonuç ve Tartışma}

$\mathrm{Bu}$ çalışmada, farklı zemin profilleri ele alınarak bu zemin profillerinde yer alan ince ve iri daneli zeminlerin bir temellerin oturma hesabı için gerekli tüm laboratuvar deneyleri yapılması amaçlanmıştır. $\mathrm{Bu}$ analizler sonucunda zemin profillerinin oluşmasından sonra temelde oturma hesabı yapılmıştır. Oturma hesabı yapılabilmesi için gerekli veriler PLAXIS 3D üç boyutlu analiz amaçlı bir sonlu eleman paket programı ile yapılarak sonuçlar çalışmanın amacına uygun olarak karşılaștırılmıştır. Deneyler sonucunda elde edilen veriler değerlendirildiğinde;

i. Yüksek plasitisiteli kil numunesinin su 
muhtevasının arttıkça kuru birim hacim ağırlığının azaldığını, düşük plastisiteli kil numunesinin su muhtevası azaldıkça kuru birim hacim ağırlığının arttığı belirlenmiştir.

ii. Optimum su muhtevası ve maksimum kuru birim hacim ağırlığında hazırlanan yüksek plastisiteli kil numunesi ve düşük plastisiteli kil numunesinin konsolidasyon deneyi öncesi boșluk oranları birbirlerine çok yakınken deney sonrasındaki değișimler numunelerin sırasıyla (A, ve C) \%6,1, \%8,5 oranlarında azaldığı belirlenmiştir.

iii. Konsolidasyonlu-drenajsı(CU) deneylerinde yüksek plastisiteli kil numunesinin düşük plastitisiteli kil numunelerine göre elastisite modülünün $\left(\varepsilon_{50}\right)$ azaldığı belirlenmiştir.

iv. Oturma hesaplarında kullanılan numunelerin zemin profillerine etki ettikleri gerilmeler hacimsel sıkışma katsayısına etkilediği belirlenmiştir. Düşük plastisiteli kil numunesi olanın temele etkidiği gerilme yüksek plastisiteli kil numunesinden daha fazla olduğu belirlenmiştir. Hacimsel sıkışma katsayısı gerilmenin fazla olduğu noktada daha az belirlenmiştir.

v. Geleneksel yöntemle hesaplanan oturma miktarı düşük plastisiteli zemin numunesinde daha az olduğunu belirlenirken yüksek plastisiteli zemin numunesinde daha fazla oturma miktarı hesaplanmıștır. Hacimsel sıkışma katsayısının oturma miktarıyla doğru oranda arttığı belirlenmiştir.

vi. Temellerin oturma hesabında çalışmamız için kullanılan sonlu elemanlar paket programının geleneksel yöntem yolluyla \%1 'den daha az hata oranıyla hesaplandığı belirlenmiştir.

vii. PLAXIS 3D yazılımıyla yapılan oturma miktarlarının geleneksel yöntem yollarına göre hemen hemen aynı sonuç verdiği belirlenmiştir.

Yapılan deneyler sonucunda temellerin oturma hesabında geleneksel yöntem ve sonlu elemanlar yöntemi karşılaştırıldığında PLAXIS 3D programının kullanılabileceği belirlenmiştir. Geleneksel yöntem yolları paket programların hesabına göre daha uzun sürede elde edildiğinden bu yazılımın hem zaman açısından hem de daha doğru sonuçlar vermesi amacıyla temel projelerinde oturma miktarlarının analizi bu paket programiyla yapılabileceği belirlenmiştir.

\section{Teşekkür}

$\mathrm{Bu}$ çalışma Süleyman Demirel Üniversitesi Bilimsel Araştırma Projeleri Koordinasyon Birimi tarafından 4556-YL1-16 nolu proje kapsamında desteklenmiştir.

\section{Conflict of Interest / Çıkar Çatışması}

Yazarlar tarafından herhangi bir çıkar çatışması beyan edilmemiştir.

No conflict of interest was declared by the authors.

\section{Kaynaklar}

Adatepe Ş., Gökalp, A., Düzceer, R., 2012. İstanbul Grovaklarında Yapılan Bir Derin Kazı Uygulamasında Değişik İksa Sistemlerinin Performansı. Zemin Mekaniği ve Temel Mühendisliği Ondördüncü Ulusal Kongresi , Süleyman Demirel Üniversitesi, Isparta, 431-442.

Avcı G., Tuncan A., 2008. Kazıklı Temellere Etki Eden Dinamik Yüklerin Statik Yükler Cinsinden Uygulanabilirliği. Zemin Mekaniği ve Temel Mühendisliği Onikinci Ulusal Kongresi, Selçuk Üniversitesi, Konya.

Bağrıaçık, B., Laman, M., 2010. Yüzeysel Temel Geometrisinin Zeminlerde Oluşan Gerilmelere Etkisinin Araştırılması. Çukurova Üniversitesi Mühendislik Mimarlık Fakültesi Dergisi. Cilt:25, Sayı:1-2.

Brinkgreve, R.B.J., Broere, W., And Waterman, D., 2004. PLAXIS Finite Element Code For Soil And Rock Analysis. 2d -Version 8.6.

Çetin, Z., Onur, M.İ., Tuncan, M., Tuncan, A., 2012. Derin Kazı Destek Sistemlerinde Yanal Deformasyonun Belirlenmesi. Zemin Mekaniği ve Temel Mühendisliği Ondördüncü Ulusal Kongresi, Süleyman Demirel Üniversitesi, Isparta, 403-412.

Ekinci, C.E., Orakoğlu, M.E., 2013. Zemin Gerilmelerinin Sayısal Gerilme Çözümlemesi Yöntemiyle Tahmini. SDU International Technologic Science. Cilt:5, No:1, 121-127.

Enkhtur, O., Nguyen, T.D., Kim, J.M., Kim, S.R. 2013. Evaluation of settlement influence factors of shallow foundation by numerical analyses. KSCE Journal of Civil Engineering, 17(1), 85-95.

Mısır, G., Laman, M., 2015. Tabakalı Zeminlere Oturan Dairesel Temellerin Deney ve Analitik Yöntemle İrdelenmesi. Çukurova Üniversitesi Mühendislik Mimarlık Fakültesi Dergisi. 30(19), 249-256.

Örnek M., Türedi Y., Dal, K., 2014. Kum Zemine Oturan Eksantrik Yüklü Şerit Temellerin Analizi, Zemin Mekaniği ve Temel Mühendisliği 2. Özel Konulu Sempozyumu, 24-25 Nisan 2014, Antalya.

Sert, S., Önalp, A., Arel, E., 2010. Sayısal Çözümlerde Zemin Özelliklerindeki Değişimin Sonuçlara Etkisi. Zemin Mekaniği ve Temel Mühendisliği Onüçüncü Ulusal Kongresi, İstanbul Kültür Üniversitesi, İstanbul, 471-482.

Subaşı E., İkizler, B., Demir, G., Angın, Z., Kayahan, A., 2012. Heyelanlar Üzerine Bir Değerlendirme (Rize İli Örneği). Zemin Mekaniği ve Temel Mühendisliği Ondördüncü Ulusal Kongresi, Süleyman Demirel 
Üniversitesi, Isparta, 337-346.

Sünnetçi, M.O., Ersoy, H., 2016. Ünye (Ordu) Killerinin Konsolidasyon ve Plastik Özellikleri Arasındaki İlişkilerin Araştırılması. Jeoloji Mühendisliği Dergisi. 40 (1), 89-102.

Türedi, Y., Örnek, M., 2015. Dikdörtgen Temel Altında Gerilme ve Taşıma Gücü Analizi. Çukurova Üniversitesi Mühendislik Mimarlık Fakültesi Dergisi. 30(2), 1-11.

Yılmaz, M.K., Çelik, S., 2012. Kil Zeminin Şişme Basıncı ve Konsolidasyon Özelliklerine Öğütülmüş Kumun Etkisinin Araştırılması. KSU Mühendislik Bilimleri Dergisi. 15(2). 